\title{
COMMUNICATIONS
}

\section{RETINOPATHY OF PREMATURITY (RETROLENTAL FIBROPLASIA) IN CHILDREN IN WHOM THE DISEASE HAS NOT PROGRESSED TO COMPLETE BLINDNESS, AND THE SUBSEQUENT INVESTIGATION OF CASES OF MYOPIA*}

\author{
BY \\ IRENE D. R. GREGORY
}

London

THE CLINICAL course of the eye disease in children known as retrolental fibroplasia is now well established as the result of observations from many workers in different countries. The long-term results of the disease in incomplete cases are still uncertain, since the condition is of recent origin. While recording the progress of these incomplete or abortive cases, information was obtained which appeared to give a new aspect to the causation of myopia.

\section{Summary of Findings on Retrolental Fibroplasia}

The term retrolental fibroplasia was coined by Terry $(1942 ; 1945)$, who described the condition as an eye disease syndrome in which vascularized connective tissue developed behind the lens during the first months of life. Terry was the first to associate retrolental fibroplasia with prematurity and, in his series of 117 cases, only eight occurred in full-term infants. King (1950) reported the findings in 238 cases, including Terry's original patients. The incidence of the disease was found to vary inversely with the birth weight. Clinical observers agree that retrolental fibroplasia is almost always bilateral, though it may be much more extensive in one eye than the other.

At the stage of full development of the disease, which is usually between 4 and 6 months after birth, the eyes show a varying degree of microphthalmos, because for some reason they fail to develop normally after the membrane has formed. King noted that an eye with a complete membrane is smaller than its fellow eye with an incomplete membrane. A comparison may be drawn here with rubella cataract, in which condition microphthalmos also occurs, and is noticeable in monocular involvement of the lens, when comparison can be made with the unaffected eye. Gregg (1941) observed microphthalmos in two-thirds of his cases of unilateral cataract, and Swan, Tostevin, Moore, and Black (1943) and Swan (1944) found, on post mortem examination of one case of monocular cataract, that the volume of the cataractous eye was only three-quarters that of the normal eye. 
In retrolental fibroplasia, where partial membranes are present, they are frequently triangular in form, with the base of the triangle placed peripherally in the region of the pars plana and ciliary body, and the apex pointing back towards the disc. The membrane in such cases occurs most frequently on the temporal side of the globe, while localized areas of retinal detachment may be present and persist. Retinal and vitreous haemorrhages may also occur.

Clinical Course.-In its acute phase this is characterized ophthalmoscopically by dilatation and tortuosity of the retinal vessels, vitreous hazing, oedema of the retina with transudation of fluid, new vessel formation in the retina, and retinal detachment. Certain authors state that vascular constriction in the retina precedes the vasodilatation, which would agree with the experimental findings in the kitten retina by Ashton and Cook (1953, 1954). Tortuosity of the vessels is generally regarded as the first sign of the disease (Kauffman, 1950; Lamotte and Tyner, 1950). Some observers regard vitreous haze as a fundamental diagnostic feature, but others do not mention it. Tyner (1951) and Fletcher (1953) report hazy ocular media as a common occurrence in premature babies, whether they develop retrolental fibroplasia or not.

In the cicatricial phase, varying clinical manifestations occur, a complete retrolental membrane or a partial one, as previously described. In addition, disc malformations, pallor, and pigmentation of the fundus with attenuation of the retinal vessels, have all been noted. Shallowness of the anterior chamber, posterior synechiae, corneal opacities, cataract, and secondary glaucoma are frequent manifestations in the terminal stages of retrolental fibroplasia.

The microphthalmos which occurs has already been mentioned. When the disease has progressed to blindness, nystagmus of a 'searching' type is present. Photophobia is a common clinical finding in retrolental fibroplasia in the acute phase.

Pathology.-The pathological findings have been divided into three stages by Ashton (1954):

Stage 1 consists in an excessive proliferation of vasoformative tissue in the inner retinal layers. This tissue breaks through the internal limiting membrane, and, at the same time, protein transudates seep through the retina and into the vitreous.

Stage 2 is characterized by an extension of the fibro-vascular tissue into the vitreous, with formation of strands of fibrous tissue. The retina commences to detach.

Stage 3 consists in an extension of the fibrous tissue formation which, by contracture, completes the detachment of the retina. Heath (1950), referring to a retinopathy of premature birth, noted that the anterior loop of uncoapted redundant retina lay in a region of the greatest ocular growth and activity. At this period, the ciliary body and processes are differentiating and the lens becoming flatter and less spherical. 
Krause (1946) considered that retrolental fibroplasia is a neuroectodermal disease, the brain as well as the eye being affected. Dickens (1946) found some experimental evidence in support of this view in his work on the metabolism of rat brain slices, which might be irrevocably altered by excessive oxygen.

The effect of oxygen on developing retinal vessels has been investigated and amply documented by Ashton, Ward, and Serpell (1954), and by Ashton and Cook (1954). These experiments on the developing kitten retina led to the conclusion that the vaso-obliterative effect of oxygen was confined to the retinal vessels and that the severity of the vaso-obliteration was most marked in the least mature vessels. In mature blood-vessels, vaso-obliteration could not be produced. The time required to produce vaso-obliteration was found to be 36 hours in the most vulnerable age groups. On transfer to air, the obliterated vessels only partially re-opened, and an abnormally proliferative vascular network developed as a result of oxygen deficiency in the retina. After total obliteration of the blood-vessels had taken place, fresh blood-vessels were formed from the disc in a profuse and disorderly manner, unlike the regular, layered arrangement of blood-vessels in the normal retina. In the early stages, the retinal vaso-constriction was reversible; the concentration of oxygen administered was also of importance. It appears that the obliterative process represents a specific effect of oxygen on growing vessels, which is in direct proportion to the immaturity of the retinal vessels, the duration of exposure to oxygen, and the degree of oxygen concentration.

Although oxygen is the predominant factor in the aetiology of retrolental fibroplasia, there may well be other contributory factors, since a few cases have occurred in the absence of oxygen therapy. Physiologically, an alteration in the oxygen concentration of the baby occurs at birth, owing to the fact that the oxygen saturation of the foetal blood is approximately 50 per cent., and that this rises to about 90 per cent. after birth. This change in oxygen tension acting on immature retinal tissue may account for some of the isolated cases of retrolental fibroplasia which have occurred where no oxygen therapy has been given, and it may, in other cases, give rise to a less obvious retinopathy.

Association of Prematurity with Ocular and Other Defects.-A birth weight of less than $5 \frac{1}{2} \mathrm{lb}$. is the standard criterion for prematurity. In 1950, it was estimated that 23 per cent. of babies weighing less than $3 \mathrm{lb}$. at birth, developed retrolental fibroplasia, and that 7 per cent. of those under $4 \frac{1}{2} \mathrm{lb}$. and 5 per cent. of those over $4 \frac{1}{2} \mathrm{lb}$. at birth, were affected.

The eye defects in prematurely-born children examined between the ages of 5 and 17 years were investigated by Eames (1946). He compared 155 of these children with 439 children born at full term, with a birth weight of $5 \frac{1}{2} \mathrm{lb}$. or over. The prematurely-born showed an increased incidence of low visual acuity at all ages, with less hypermetropia, and more myopia, as compared 
with the children born at full term. In addition to the ocular findings, the greatest difference between the full-term group and the prematurely-born was seen in the incidence of feeble-mindedness, which was 3 per cent. more frequent in the premature children, together with an increased tendency to nervous disorders and speech defects. Potter (1954) found a high incidence of mental defect in his series of 151 children suffering from retrolental fibroplasia, 20 per cent. being definitely mentally defective, while a further 26 per cent. were retarded though probably capable of receiving education. In this series of cases, the figures suggested an inverse relationship between birth weight and mental deficiency, the incidence of which, in babies weighing between 2 and $3 \mathrm{lb}$. at birth, was 23.7 per cent., roughly double that of babies weighing between 4 and $5 \mathrm{lb}$., in whom the incidence was 12.5 per cent. These figures lend support to the view that other tissues besides the ocular ones, particularly the nervous tissues, are involved in retrolental fibroplasia.

Relationship of the Developing Fundus Oculi of the Premature Infant to Retrolental Fibroplasia.-This has been investigated by Fletcher (1953), who examined 320 premature infants weighing less than 2,500 g. $\left(5 \frac{1}{2} \mathrm{lb}\right.$.) at birth. It was found that half of the babies weighing less than 1,500 g. (approx. $3 \mathrm{lb}$. $5 \mathrm{oz}$.) showed an immature fundus which remained stationary for several weeks and then differentiated rapidly (in about a fortnight) into a mature fundus. The immature fundus showed vitreous clouding which tended to obscure fundus details. These, when seen, included an oval disc with small bloodvessels, while the mature fundus presented a spherical disc, bloodvessels of adult distribution, and a clear vitreous.

Babies with retrolental fibroplasia tended to show evidence of increased intra-ocular pressure, while babies with retrolental fibroplasia, and small premature babies, were found to have a high and fluctuating myopia on ophthalmoscopic examination.

\section{Summary of the Case Records in Thirty Children with Retinopathy of Prematurity}

The scope of this inquiry comprises the findings in thirty children who were examined from the ocular standpoint. A follow-up examination of children who were known to have had retrolental fibroplasia in infancy was planned. The examination was arranged of those children with incomplete retrolental membranes, in whom some degree of vision could be expected. The records of children with retrolental fibroplasia available to the London County Council for the period 1947-1953 were investigated, and it was found that the proportion of incomplete or abortive cases was 25 per cent. of the total. Further, where one of twins was reported blind as a result of retrolental fibroplasia, the eyes of the other twin were examined. The clinical picture in those children who were known to have developed retrolental fibroplasia is a typical one, and includes, in the majority of cases, a myopic error of refraction, which could not be accounted for on a familial basis. 
During the examination of certain cases of myopia occurring in children of school age, it became apparent that the clinical picture, which in several cases had been accepted as consistent with the appearances of congenital myopia, resembled that found in the abortive cases of retrolental fibroplasia. Subsequent inquiry revealed that all of these children had been born prematurely. The case reports of these children are appended separately, and, since prematurity is represented in both groups, the findings in the total number of cases have been analysed. Where possible, the subjective findings of the refraction are given in the case reports, but where this proved impossible, the retinoscopy findings under atropine cycloplegia are recorded.

Refractive Error.-The refractive error encountered in 85 per cent. of the cases was a myopia varying from $-2 \cdot 5$ to $-18 \mathrm{D}$. Where the two eyes were unequally affected by the retinopathy of prematurity, it was the eye with the better vision which showed the myopia, and where retinoscopy was possible in the more severely affected eye, a hypermetropic or emmetropic refraction was found. The significance of these findings will be discussed later.

The corrected visual acuity did not exceed 6/12, even in those cases with the least fundus changes. Where it has been possible to follow up these cases, the evidence suggests that, in the great majority, the myopia has not progressed. One of the exceptions to this in the present series was Case 19, one of triplets, who showed an increase in myopia of the order of -3 and $-4 \mathrm{D}$. in the right and left eyes respectively over a period of 6 years, while her triplet sister (Case 20) showed virtually no change in the same period.

Nystagmus.-This was present in half the cases with useful vision. In the majority, the movement was fine and somewhat variable in rhythm, and its direction horizontal, vertical, or rotatory; frequently, the different movements were present in the same eye at different times. The two blind twins, Case 8 and Case 11, showed a typical amaurotic nystagmus, rapid, coarse and roving in nature. In one other child, Case 15, the nystagmus was probably inherited.

Eccentric fixation was associated with the nystagmus in five cases.

Microphthalmos. - Of the 28 cases, fourteen showed unilateral microphthalmos. The microphthalmic eye usually possessed little vision and frequently showed a convergent squint.

Strabismus.-Seventeen cases (60 per cent.) in the series showed strabismus. Sixteen of these were convergent squints, and one also showed vertical imbalance due to a secondary over-action of the inferior oblique. The other case showed a latent vertical heterophoria. Usually, the strabismus was secondary to the eye disease which had led to gross visual impairment of the squinting eye.

Ocular Media.-Opacities in the ocular media were frequently encountered. 
Three grossly damaged eyes showed corneal opacities, and one case presented lenticular opacities. Vitreous opacities were evident in two-thirds of the cases.

Disc.-Malformations of the optic nervehead were noted in fourteen cases. The appearance in some cases was that of a coloboma of the disc, while in others the disc appeared to be distorted as the result of contracture of scar tissue. Remnants of glial tissue were seen at the nervehead. Distortion of the nervehead was suggested by the tortuous course of the retinal bloodvessels as they emerged from the disc.

Retina and Choroid.-Thinning, atrophy, and depigmentation of the retina were commonly encountered. Large areas of scarring with pigment disturbance were seen in many fundi where the disease process had been moderately severe; in the most minimal cases, a fine pigmentary mottling of the "pepper-and-salt" variety was apparent at the periphery of the fundi. A "bone corpuscle" type of pigmentation was also noted in some of these cases.

The macula in certain cases appeared elevated and slate-grey in colour, whilst in others it looked red and granular. A fine stippling of pigment was evident in many cases.

The retinal vessels sometimes showed an increased tortuosity, and a diminution in the calibre and number of branches was also noted.

Retinal Detachment.-This was evident in fourteen cases. In thirteen of these, the detachment was localized, the area most often involved being in the temporal half of the globe. Frequently the detachment was triangular in shape, with the apex of the triangle pointing towards the disc and the base in the region of the ciliary body. Two cases developed a retinal detachment at the age of 5 years, whilst in another a vitreous haemorrhage developed (which subsequently cleared up) at the same age.' A third child, now aged 6 , has recently been reported as developing a retinal detachment.

Retinal Folds.-These were apparent in five cases, and in one case retinal folds extended downwards and laterally from the disc in both eyes, the symmetrical, bilateral appearance suggesting a genetically determined lesion.

\section{Significance of Findings}

The myopic refractive error occurred in such a high proportion of these cases that, although the series is small, there is ground for suggesting that the association is a real one. The precise nature of the connexion between the two is by no means clear; myopia does not appear to occur in the eyes which are severely affected, and, as has been previously mentioned, where the two eyes are unequally affected, it is the eye with useful vision which shows the myopia. It is possible that the myopia develops through the weakening of the globe by disease, but this hypothesis does not explain the 
finding of a hypermetropic refraction in the more severely affected eye. This latter finding may be analogous to the unilateral microphthalmos which may occur in rubella with uniocular lens changes.

The noxious effect of the rubella virus on the developing eye occurs in the first 3 months of pregnancy, and the effect of prematurity on the eye takes place in the neonatal period, yet there appears to be some fundamental resemblance between the two in their effect on ocular development in that both cases may represent an arrest of development. The myopic refractive error may be a manifestation of abnormal growth; a similar hypothesis has been put forward by Steiger (1913) and Vogt (1924) to the effect that the development of high myopia is determined primarily by an overgrowth of the retina, which is the master-tissue, the enlargement of the globe being secondary to the overgrowth. This theory did not take environmental factors into account, however.

Clinically, the findings in these myopes bear resemblances to other clinical types already described in text-books as congenital axial myopia. In most cases, the diagnosis of congenital myopia is not made until the second or third year of life. The commonest clinical picture described in the cases of congenital myopia recorded hitherto is that of "partial albinism", where the interior of the eye is lacking in pigment. It is postulated that, in this condition, the inner eye alone is affected, the remainder of the body being normally pigmented. Brückner and Franceschetti (1932) recorded the findings in 25 cases of myopia characterized by attenuation of the retinal vessels and a dusky, mottled appearance of the macula; the parents of the children in this series were not myopic.

The myopia occurring in these cases is obviously developmental in origin, but the diagnosis is incomplete, since it has not, so far, been found practicable to examine these children and determine what components in the refractive system of the eye are responsible, and in this connexion, further research is obviously indicated. The myopia may be caused by changes in the refracting media or axial length of the eye; either of these factors or a combination of both may be responsible. An increase in the curvature of the cornea may occur, depending on the growth and elasticity of the cornea and sclera and the intra-ocular pressure. Since the opening of the angle of the anterior chamber is a slow process, occurring relatively late in foetal life, this comparatively inadequate drainage system may lead to a stretching of the coats of the eye, and hence to myopia. Where a rise in ocular tension occurs in this way, as in buphthalmos, the refraction is not necessarily myopic, owing to a flattening of the cornea and lens, which compensates for the increase in axial length.

Changes in the structure of the lens may be a causative factor in myopia. From the third to the 8th month of foetal life, the lens is increasing in size and becoming more spherical. The ciliary muscle develops at the fifth month, when the meridional portion of the muscle is well differentiated. By 
the sixth month, the circular fibres may be recognized, and accommodation in the premature child is therefore possible and cannot be ruled out as a cause of the fluctuating myopia which has been reported.

A change in the composition of the fluid media may occur in acute stages of retrolental fibroplasia as a result of the transudation of protein exudates through the walls of the dilatated and tortuous retinal vessels. The higher refractive index caused by the increased protein could lead to a myopic refraction, but this state of affairs would be unlikely to persist for any length of time. An increase in the axial length of the eye has long been considered an important factor in the aetiology of myopia. Keeney (1951) states that the length of the foetal eye increases from 14 to $17 \mathrm{~mm}$. during the last 3 months of foetal life; during this period, the eyes of premature children are exposed to a radical change in environment and the coats of the eye, though formed, are thin and very elastic.

The nystagmus, in these cases, is, needless to say, ocular in type. Ocular nystagmus occurs in many conditions where fixation is difficult or impossible, although, in one sense, nystagmus differs only in degree from normal fixation, in which the eye is never absolutely motionless. When a normal eye is looking steadily at a given object, constant muscular activity occurs to ensure that the actions of the various muscles are balanced against one another, and this constant activity leads to fine rotatory movements of the eye. Nystagmus may thus be looked upon as an adaptation to attempt to achieve fixation, in spite of obstacles, by exaggerated effort. The nystagmus, in these cases, can be regarded as the result of impaired function of the macula, the abnormal structure of which can be seen ophthalmoscopically in many of these children. The eccentric fixation may be of similar origin, but may arise as the result of displacement of the macula by traction of scar tissue in the periphery of the retina.

All the squints which were observed occurred in eyes grossly affected by disease. Binocular vision can only be developed when the vision of the two eyes is equal. Where the vision of the two eyes is unequal, development of the normal binocular reflexes is hampered. If the function of an eye is severely impaired in early childhood, accommodation leads to excessive convergence, which is not controlled by the binocular reflexes, and a convergent squint ensues. This would appear to have been the sequence of events in these children.

The vitreous opacities can be readily explained as a sequel to the angioblastic process in the vitreous and the associated transudation of protein. Fletcher (1953) found that the vitreous in premature babies is cloudy for several weeks and clears subsequently, the ultimate progress of the eye depending on whether it has developed retrolental fibroplasia or not.

The colobomatous appearance of the disc in many of these cases was due to distortion of the blood-vessels and glial tissues through traction by scar 
tissue in the fundus. It is possible that the appearance in other cases was that of a true coloboma, which is due to deformities of the primitive epithelial papilla (Mann, 1937).

The fundus appearances are consistent with the end-results of a disturbance of vascular origin. Fine pigmentation of the "pepper-and-salt" variety was noted, and the retina was often found to be albinotic, thin, and atrophic. With reference to albinism, Mann (1937) states that the differentiation of the macula, which is not completed until 6 months after birth, is related in some way to normal pigmentation and to the formation of a clear image on the retina. Keeney (1951) says that the stimulation of light appears to be necessary to the completion of retinal development. The lack of pigment in these cases may be due to the retinal atrophy which occurs as a sequel to the acute phase of retrolental fibroplasia; it is also possible that the pathological process may interfere with the development of choroidal pigment which occurs in the sixth month of intra-uterine life. The differentiation of the macula may be hindered through environmental disturbances at the crucial period of development. The frequent localization of retinal detachments in the temporal half of the globe is thought to have some connexion with the impaired function of the macula. Michaelson (1954) investigated, histologically, the vascular system in the eyes of man and animals, and found in the developing human retina that the upper temporal vessels are nearly always longer than the lower. In the same fundus, both temporal vessels are always longer than the nasal vessels when measured from the edge of the disc. The difference in length is not due to a difference in the rates of growth. It could be due to different starting times or to a difference in the area of retina to be traversed. The area of retina temporal to the disc is 50 per cent. greater than that of the nasal portion and contains more ganglion cells. Michaelson suggests that new vessel formation is a function of retinal activity, which is probably greater on the temporal side. Another hypothesis is that the greater distance to be traversed by the temporal vessels may delay maturation of the vascular pattern of the temporal side of the retina. This immaturity could produce a susceptibility to anoxia. In all these considerations, the macula, being on the temporal side of the disc, is involved.

The retinal detachments have all occurred in the first 8 years of life, during which period a great increase in axial length occurs. This increase averages $8 \mathrm{~mm}$. in normal eyes. It is possible that the detachments are associated with a stress between the enlarging sclera on the one hand and the scarred retina on the other.

\section{Summary}

In view of the finding that retinopathy of prematurity is associated with myopia, and that in certain cases it has been possible to correlate myopia with prematurity, it is suggested that the association between the two is a real one, and that prematurity is one of the factors in the causation of myopia. The new finding, in itself, provokes further inquiry as to the nature of the 
myopia and the mechanism of its production. More use might be made of the term, retinopathy of prematurity, in view of the wide variety of clinical findings covered by this title.

I should like to record my indebtedness to Sir Stewart Duke-Elder for his kindness in perusing this paper.

\section{REFERENCES}

Ashton, N. (1954). British Journal of Ophthalmology, 38, 385. and Cook, C. (1953). Ibid., 37, 193.

(1954). Ibid., 38, 433.

, WARD, B., and SerPell, G. S. (1954). Ibid., 38, 397.

Brückner, A., and Franceschett, A. (1932). Arch. Augenheilk., 105, 1.

DiCKENS, F. (1946). Biochem. J., 40, 145.

EAmes, T. H. (1946). Amer. J. Ophthal., 29, 57.

FletCHER, M. C. (1953). Pediat., 43, 499.

GregG, N. MCAlister (1941). Trans. ophthal. Soc. Aust., 3, 35.

HeATH, P. (1950). Arch. Ophthal. (Chicago), 44, 245, 491.

KAUFFMAN, L. (1950). Ibid., 44, 623.

KeENEY, A. H. (1951). "Chronology of Ophthalmic Development" (Amer. Lecture Series No. 99). Thomas, Springfield, Ill.

KING, M. J. (1950). Arch. Ophthal. (Chicago), 43, 694.

KRAUSE, A. C. (1946). Ibid., 36, 387.

LAMO'TTE, - ., and TYNER, G. S. (1950). Ibid., 44, 620.

MANN, I. (1937). "Developmental Abnormalities of the Eye". University Press, Cambridge.

Michaelson, I. C. (1954). "Retinal Circulation in Man and Animals". Thomas, Springfield, Ill.

PotTer, C. T. (1954). Proc. roy. Soc. Med., 47, 715.

STEIGER, A. (1913). "Die Entstehung der sphärischen Refraktionen des menschlichen Auges". Karger, Berlin.

Swan, C. (1944). J. Path. Bact., 56, 289. , Tostevin, A. L., Moore, B., Mayo, H., and Black, G. H. Barham (1943). Med. J. Aust., 2, 201.

Terry, T. L. (1942). Amer. J. Ophthal., 25, 203. (1945). J. Amer. med. Ass., 128, 582.

TyNer, G. S. (1951). A.M.A. Arch. Ophthal., 45, 627.

VoGT, A. (1924). Ber. ophthal. Ges. Heidelberg., 44, 67.

\section{APPENDIX}

\section{Case Reports}

(A) Cases in which the diagnosis of retrolental fibroplasia had already been made.

Case 1, male, born 5.6.51, at 7 months, birth weight $3 \mathrm{lb}$., in oxygen tent 5 weeks.

Right eye showed a good red reflex and fixed eccentrically. A fine nystagmus was present. Iris blue. The fundus oculi showed distortion of the disc and fine pigmentary stippling in the macular region. Retinoscopy under atropine revealed a myopia of -3 dioptres.

Left eye convergent and microphthalmic, anterior chamber shallow, iris atrophic and discoloured. The fundus showed an extensive retinal detachment in the inferior half of the globe. No retinoscopy was possible.

Case 2, male, born 14.3.49, 10 weeks premature, birth weight $2 \mathrm{lb}$., in oxygen tent 6 weeks, very frail physique, one of twins, the remaining twin having died shortly after birth.

Both eyes showed a fine nystagmus.

Right eye smaller than left, anterior chamber shallow. Iris hazel brown. The lens was clear, but the vitreous showed numerous fine opacities. A detached fold of retina ran downwards and nasally from the disc, occupying the lower nasal quadrant of the globe. The retina elsewhere showed patchy pigmentation near the equator. Visual acuity-hand movements. Retinoscopy showed refraction $-2.5 \mathrm{D}$ sph., $-3 \mathrm{D}$ cyl., axis $180^{\circ}$. Correction of myopic astigmatism did not improve acuity. 
APPENDIX TABLE

PARTICULARS OF THIRTY CASES

\begin{tabular}{|c|c|c|c|c|c|c|c|c|c|c|c|c|c|}
\hline \multirow{3}{*}{$\begin{array}{l}\text { Case } \\
\text { No. }\end{array}$} & \multirow{3}{*}{ Sex } & \multirow{3}{*}{$\begin{array}{c}\text { Date } \\
\text { of } \\
\text { Birth }\end{array}$} & \multirow{3}{*}{$\begin{array}{l}\text { Period } \\
\text { of } \\
\text { Gesta- } \\
\text { tion } \\
\text { (mths) }\end{array}$} & \multirow{2}{*}{$\underset{\text { Weight }}{\text { Birth }}$} & \multirow{3}{*}{$\begin{array}{c}\text { Time } \\
\text { in } \\
\text { Oxygen } \\
\text { Tent } \\
\text { (wks) }\end{array}$} & \multicolumn{6}{|c|}{ Refraction } & \multirow{2}{*}{\multicolumn{2}{|c|}{ Visual Acuity }} \\
\hline & & & & & & \multicolumn{3}{|c|}{ Right } & \multicolumn{3}{|c|}{ Left } & & \\
\hline & & & & lb $o z$ & & D sph. & D cyl. & axis & D sph. & D cyl. & axis & Right & Left \\
\hline $\mathbf{I}$ & $\mathbf{M}$ & 5.6 .51 & 7 & 30 & 5 & -3 & & & & & & \multicolumn{2}{|c|}{ not ascertainable } \\
\hline 2 & $\mathbf{M}$ & I4.3.49 & $6 \frac{1}{2}$ & 20 & 6 & $-2 \cdot 5$ & -3 & $180^{\circ}$ & $-I \cdot 5$ & -2 & $90^{\circ}$ & $\mathbf{H M}$ & $3 / 60$ \\
\hline 3 & $\mathbf{F}$ & 8.9 .48 & 7 & 20 & 6 & -2 & & & \multicolumn{3}{|c|}{ emmetropic } & \multicolumn{2}{|c|}{ not ascertainable } \\
\hline 4 & $\mathbf{M}$ & 23.2 .50 & 7 & 36 & $\underset{\text { known }}{\text { not }}$ & 一 & - & - & $-\mathbf{I I}$ & $-2: 5$ & $180^{\circ}$ & No PL & $6 / 24$ \\
\hline 5 & $\mathbf{M}$ & I6.12.49 & 6 & 30 & 6 & -18 & $-I \cdot 5$ & $15^{\circ}$ & +6 & - & - & $6 / 36$ & No $P L$ \\
\hline 6 & $\mathbf{M}$ & I5.4.49 & 7 & 39 & 2 & +4 & & & & & & CF & $\mathbf{P L}$ \\
\hline 7 & $\mathbf{F}$ & \multirow{2}{*}{25.6 .51} & \multirow{2}{*}{$7 \frac{1}{2}\{$} & 312 & 3 & $-6 \cdot 5$ & -0.5 & $180^{\circ}$ & $-6 \cdot 5$ & $-1 \cdot 5$ & $180^{\circ}$ & \multicolumn{2}{|c|}{ not ascertainable } \\
\hline 8 & $\mathbf{M}$ & & & 3 I & 5 & & & & & & & PL & PL \\
\hline 9 & $\mathbf{M}$ & 19.6.50 & $6 \frac{1}{2}$ & 35 & 6 & -2 & +3 & $90^{\circ}$ & $-I \cdot 5$ & +4 & $180^{\circ}$ & $6 / 60-6 / 36$ & $6 / 60-6 / 36$ \\
\hline 10 & $F$ & \multirow{2}{*}{24.10 .51} & \multirow{2}{*}{$\underset{\substack{\text { tion } \\
\text { uncer- } \\
\text { tain }}}{\text { dura- }}\{$} & 33 & 4 & $+I \cdot 5$ & & & $+I$ & & & \multicolumn{2}{|c|}{ not ascertainable } \\
\hline II & $\mathbf{M}$ & & & 2 II & 4 & & & & & & & \multicolumn{2}{|c|}{ not ascertainable } \\
\hline 12 & $F$ & 16.8 .46 & 6 & 22 & 12 & - & - & - & -9 & -2 & $155^{\circ}$ & No PL & $6 / 18-I$ \\
\hline I3 & F & 12.8.46 & 6 & 20 & $\underset{\text { known }}{\text { not }}$ & - & - & - & $-I$ & $-I$ & $90^{\circ}$ & No PL & $4 \cdot 60$ \\
\hline 14 & $\bar{M}$ & I6.3.50 & 6 & 24 & 8 & - & - & - & -7 & & & No PL & $6 / 36$ \\
\hline Is & $\mathbf{F}$ & 16.4 .47 & $6 \frac{1}{2}$ & 28 & several & - & $+2 \cdot 75$ & $45^{\circ}$ & - & $+2 \cdot 75$ & $120^{\circ}$ & $6 / 24 \mathrm{pt}$ & $6 / 24$ \\
\hline 16 & $\mathbf{M}$ & 24.7 .48 & 7 & 28 & 3 & -4 & -0.75 & $15^{\circ}$ & -0.75 & -0.75 & $180^{\circ}$ & $3 / 60$ & $3 / 60$ \\
\hline 17 & $\mathbf{M}$ & 25.5 .50 & 7 & 28 & 8 & -15 & -2 & $90^{\circ}$ & +2 & - & - & $6 / 36$ & No PL \\
\hline 18 & $\mathbf{F}$ & 29.4 .47 & 8 & 312 & 4 & -7 & -0.5 & $90^{\circ}$ & -7 & -0.5 & $80^{\circ}$ & $6 / 12$ & $6 / 12$ \\
\hline \multirow{2}{*}{19} & \multirow{2}{*}{$\mathbf{F}$} & \multirow{4}{*}{3.4 .42} & \multirow{4}{*}{$\left.7 \frac{1}{2}\right\}$} & 2 I0 & not & $\begin{array}{r}1949: \\
-4 \\
\end{array}$ & $-I$ & $180^{\circ}$ & -9 & $-\mathbf{I}$ & $180^{\circ}$ & $6 / 18$ & $6 / 18$ \\
\hline & & & & & known & $\begin{array}{c}1955: \\
-7 \\
\end{array}$ & $-\mathbf{I}$ & $180^{\circ}$ & -13 & $-\mathbf{I}$ & $180^{\circ}$ & $6 / 18$ & $6 / 18$ \\
\hline & $\mathbf{F}$ & & & & not & $\begin{array}{r}1950: \\
-10 \\
\end{array}$ & $-\dot{I} \cdot 5$ & $170^{\circ}$ & -12 & -2 & $120^{\circ}$ & $6 / 18$ & $6 / 18$ \\
\hline 20 & $\mathbf{F}$ & & & 212 & known & $\begin{array}{r}1955: \\
-11 \\
\end{array}$ & & & -13 & & & $6 / 18$ & $6 / 18$ \\
\hline $2 I$ & $\mathbf{M}$ & 2.1 .47 & 7 & 48 & 9 & - & - & - & -10 & $-I \cdot 5$ & $30^{\circ}$ & CF (6 in.) & $6 \cdot 18$ \\
\hline & F & $385 \mathrm{I}$ & & & & -9 & -0.5 & $180^{\circ}$ & -5 & $-4 \cdot 5$ & $180^{\circ}$ & not ascer & ainable \\
\hline 22 & F & 3.8 .51 & 7 & 215 & 4 & -10 & -0.5 & $180^{\circ}$ & $-6 \cdot 5$ & $1-2 \cdot 5$ & $170^{\circ}$ & not ascer & ainable \\
\hline 23 & $\mathbf{F}$ & 4.6 .48 & 7 & 26 & $\underset{\text { known }}{\text { not }}$ & -9 & -2 & $55^{\circ}$ & - & - & - & $6 / 36$ & ? PL \\
\hline 24 & $\mathbf{F}$ & 5.2 .46 & $6 \frac{1}{2}$ & 24 & 8 & -5 & $-I$ & $15^{\circ}$ & - & - & - & $6 / 12$ & No PL \\
\hline 25 & $\mathbf{F}$ & 22.10 .47 & $6 \frac{1}{2}$ & 28 & 9 & -10 & - & - & -8 & -3 & $150^{\circ}$ & $6 / 12$ & $3 / 60$ \\
\hline 26 & $\mathbf{M}$ & I6.2.5I & 6 & $2 I I$ & 12 & & imetropi & & $-3 \cdot 5$ & - & - & not ascer & ainable \\
\hline 27 & $\mathbf{F}$ & I.I1.49 & $6 \frac{1}{2}$ & 212 & several & - & -3.5 & $180^{\circ}$ & -4 & -3.5 & $180^{\circ}$ & $6 / 36$ & $6 / 36$ \\
\hline 28 & $\mathbf{M}$ & I6.11.46 & $7 \frac{1}{2}$ & 30 & nil & -16 & - & - & $-\mathbf{I I}$ & - & - & $\begin{array}{c}6 / 12 \\
(6 / 9 \mathrm{pt})\end{array}$ & $4 / 60$ \\
\hline 29 & $F$ & 20.5 .48 & 7 & 32 & I & - & - & - & $-5 \cdot 5$ & $-1 \cdot 5$ & $180^{\circ}$ & PL & $6 / 36$ \\
\hline 30 & $\mathbf{M}$ & 17.3 .46 & 6 & 20 & 12 & -4.5 & $-1 \cdot 5$ & $105^{\circ}$ & - & - & - & $3 / 60$ & PL \\
\hline
\end{tabular}


Left eye showed eccentric fixation. The anterior chamber and lens were normal. The vitreous showed fine opacities. The retina showed a fold running downwards and nasally from the disc (which was drawn out and distorted) in the 8 o'clock meridian. Both upper and lower margins of the fold were sharply defined, whilst some pigmentation at the periphery of the retina elsewhere was visible. Visual acuity $3 / 60$. Retinoscopy showed refraction $-1.5 \mathrm{D}$ sph., $-2 \mathrm{D}$ cyl., axis $90^{\circ}$. No improvement was possible with lenses.

Case 3, female, born 8.9.48, 8 weeks premature, birth weight $2 \mathrm{lb}$., in oxygen tent 6 weeks.

Both eyes showed a fine rotatory nystagmus, and eccentric fixation. Irides blue. The fundus appearances were similar in the two eyes, both discs showing deep excavations resembling congenital colobomata. Retinal folds ran obliquely downwards and temporally from both discs. Subjective estimation of visual acuity was not possible, but retinoscopy showed a myopia of -2 dioptres in the right eye, which was about $20^{\circ}$ convergent, and an emmetropic refraction in the left eye.

Case 4, male, born 23.2.50, 8 weeks premature, birth weight $3 \mathrm{lb} .6 \mathrm{oz}$.

Right eye blind with no perception of light. Eye small, cornea diffusely hazy, anterior chamber obliterated. No red reflex present.

Left eye showed a fine nystagmus. Iris blue. Fine opacities were present in the vitreous, but a clear fundus view was obtained. A crescent, about one-third of a disc diameter in width, was present at the disc, with a generalized lack of pigment throughout the fundus and a very fine pigment stippling. Visual acuity, with $-11 \mathrm{D}$ sph., $-2 \cdot 5 \mathrm{D}$ cyl., axis $180^{\circ}, 6 / 24$ ptly.

Case 5, male, born 16.12.49, 3 months premature, birth weight $3 \mathrm{lb}$., in oxygen tent 6 weeks.

Right eye highly myopic, anterior segment normal. Iris grey-blue. The posterior segment showed strands of vitreous opacities. The disc appeared rather pale in colour, and had a distorted appearance suggestive of a coloboma. The retinal vessels were tortuous. The fundus as a whole appeared lacking in pigment, and at the same time the periphery showed a fine pigmentary stippling. The macula showed a fine stippling of pigment, but the area surrounding it was unpigmented. Visual acuity, with $-18 \mathrm{D}$ sph., $-1.5 \mathrm{D}$ cyl., axis $15^{\circ}, 6 / 36$.

Left eye convergent and microphthalmic, anterior chamber shallow, lens clear. Numerous vitreous opacities were present and the retina showed a detachment in the lower temporal quadrant. There was no perception of light, although retinoscopy was possible and showed a hypermetropia of +6 dioptres.

Case 6, male, born 15.4.49, at 7 months, birth weight $3 \mathrm{lb} .9$ oz., in oxygen tent 2 weeks. The baby's eyes were noticed to "roll" a good deal, and he was taken to Moorfields at the age of 3 months.

Both eyes showed a fine nystagmus with, in addition, some coarse "searching" movements. Irides brown.

Right eye showed an anterior chamber of normal depth. The lens was clear. A detached area of retina was visible in the nasal quadrant, and this projected into the retina and prevented a view of the disc. In the lower part of the retina, large whitish patches of choroidoretinal atrophy were present. Retinoscopy showed a moderate hypermetropia of +4 dioptres. Vision was counting fingers only and could not be improved.

Left eye smaller than the right, anterior segment normal. Numerous vitreous opacities were present and a retinal detachment occupied the lower half of the globe, extending horizontally from 3 to 9 o'clock. Large patches of scar tissue could be made out in the upper half of the fundus resembling those seen in the right eye. Vision was perception of light only, and retinoscopy was impossible.

Case 7, female, born 28.6.51, one of twins, 6 weeks premature, birth weight $3 \mathrm{lb} .12 \mathrm{oz}$, in oxygen tent 3 weeks. Parents not myopic.

Both eyes, media clear, fundi normal, apart from a little stippling at the macular regions. Irides brown. Retinoscopy showed a myopia of about -6 dioptres. Subjective estimation of visual acuity not possible.

Right eye refraction $-6.5 \mathrm{D}$ sph., $-0.5 \mathrm{D}$ cyl., axis $180^{\circ}$.

Left eye refraction $-6.5 \mathrm{D}$ sph., $-1.5 \mathrm{D}$ cyl. axis $180^{\circ}$. 
Case 8, male, twin brother of Case 7, birth weight $3 \mathrm{lb} .1 \mathrm{oz}$., in oxygen tent 5 weeks.

Both eyes showed coarse nystagmus and were divergent about $20^{\circ}$. Visual acuity perception of light only. Ocular tension increased, anterior chambers shallow. Irides grey. Both lenses clear, revealing an obvious retrolental membrane in both eyes, though some red reflex was visible above in the left eye.

Case 9, male, born 19.6.50, one of twins, the other twin being stillborn, at $6 \frac{1}{2}$ months, birth weight $3 \mathrm{lb}$. 5 oz., in oxygen tent 6 weeks. Parents not myopic. The child held his head turned to the left, and when looking at objects, focused eccentrically.

Both eyes showed moderate lateral nystagmus, ocular tension normal. Irides blue.

The visual acuity was impossible to assess subjectively but appeared to correspond to about $6 / 60$ or $6 / 36$, small familiar objects being readily identified. Retinoscopy showed a mixed astigmatism.

Right eye convergent, the pupil reacting to light. A large strand of opacity was present in the vitreous while glial tissue blurred the outline of the disc, the vessels at the nervehead being distorted. Refraction: $-2 \mathrm{D}$ sph., +3 Dcyl., axis $90^{\circ}$.

Left eye showed a strand of vitreous opacity and distortion of the disc, the outline of which was clear. Below the disc was a patch of pigment. Some stippling of pigment was present at the left macular region. Refraction: $-1.5 \mathrm{D}$ sph., $+4 \mathrm{D}$ cyl., axis $180^{\circ}$.

Case 10, female, born 24.10.51, one of twins, birth weight $3 \mathrm{lb} .3 \mathrm{oz}$., period of prematurity not stated, in oxygen tent 4 weeks. Father myopic.

Both eyes showed a fine nystagmus. Irides blue. Retinoscopy showed a normal, slightly hypermetropic refraction.

Right eye convergent, and rather smaller than the left. The lens was clear, but the vitreous showed numerous discrete opacities. The fundus showed a grey elevated patch of retrolental tissue in the lower nasal quadrant, and elsewhere the retina appeared thin and lacking in pigment. A wide-spread shallow detachment occurred in October, 1956. Refraction: +1.5 D sph.

Left eye anterior chamber and lens normal. Vitreous opacities were present, whilst a retinal fold ran downwards and outwards from the disc. The retina appeared thin, atrophic, and lacking in pigment. Refraction: + $1 \mathrm{D}$ sph.

Case 11, male, twin brother of Case 10, birth weight $2 \mathrm{lb} .11 \mathrm{oz}$., generally retarded and obviously totally blind.

Right eye cornea and lens clear, but dense retrolental membrane present.

Left eye small, with corneal opacities, anterior chamber obliterated.

No red reflex was obtainable in either eye, while the ocular tension, as estimated by finger pressure, was increased in the left eye.

Case 12, female, born 16.8.46, at 6 months, one of twins (the other, being more severely affected, was in a Sunshine Home and was not examined on that account), birth weight $2 \mathrm{lb} .2 \mathrm{oz}$. (twin sister's birth weight $2 \mathrm{lb}$.), in oxygen tent 12 weeks. Parents not myopic.

Both eyes. Irides blue.

Right eye small and convergent, anterior segment appeared normal. Vitreous showed numerous opacities, and the retina was extensively detached, especially on the temporal side. No retinoscopy was possible. No perception of light.

Left eye, anterior segment normal, but vitreous showed multiple fine opacities. The disc showed some distortion, with a patch of pigmentation at its temporal side. The vessels appeared very tortuous at the periphery, where there were soft creamy patches, their diameter being about three times the width of the vessels. These patches were also present in the central area but less numerous there, while the macula itself appeared greyish and raised. Retina markedly thin and lacking in pigment, choroidal vessels clearly visible. Visual acuity, with $-9 \mathrm{D}$ sph., $-2 \mathrm{D}$ cyl., axis $155^{\circ}, 6 / 18-1$.

Case 13, female, born 12.8.46, 3 months prematurely, birth weight 2 lb., length of time in oxygen tent not known.

Right eye small, showed no perception of light, deep anterior chamber. Iris muddy-grey and adherent at pupil margin to the remains of the lens, needling having been carried out on that eye in infancy. 
Left eye, anterior chamber rather shallow. Iris blue-grey. Some adhesions between iris and lens at 4 to 5 o'clock, with a finger of iris tissue running from the anterior surface of the iris to the lens. The lens showed some fine opacities, and the vitreous also showed opacities. Patches of pigmentation and atrophy were seen scattered over the periphery. Visual acuity unaided was 4/60. Retinoscopy showed a low degree of myopia and astigmatism, which, when corrected, did not improve the acuity. Refraction $-1 \mathrm{D}$ sph., $-\mathrm{D}$ cyl., axis $90^{\circ}$.

Case 14, male, born 16.3.50, 3 months premature, one of twins (the other twin having died shortly after birth), birth weight $2 \mathrm{lb} .4 \mathrm{oz}$., in oxygen tent 8 weeks. General physique poor.

Both eyes showed fine nystagmus. Irides blue.

Right eye small and showed secondary divergence. Cornea clear, pupil small, anterior chamber shallow, lens clear, dense retrolental membrane and no red reflex. No perception of light.

Left eye, anterior segment normal. A good view of the fundus was possible. The disc was slightly pale, and the fundus in general appeared pale and depigmented. Correction of the myopia of -7 dioptres, gave a visual acuity of $6 / 36$.

Case 15, female, born 16.4.47, gestation 26 weeks, birth weight $2 \frac{1}{2} \mathrm{lb}$., in oxygen tent for several weeks, exact duration unknown. General physique rather small for her age. Father short-sighted.

Both eyes showed a moderately fast nystagmus, and the appearances were symmetrical. Irides blue. The pupils and media were clear. Both discs were inverse, the vessels entering on the temporal side and becoming rather tortuous and attenuated towards the periphery of the retina. Both retinae appeared markedly thin, with very little pigment, while on the nasal sides of both discs there was some atrophy of the choroid, with baring of the sclera. Both maculae were granular and finely stippled with pigment, and some rather coarser pigmentary stippling was present at the periphery of the retina. Visual acuity in the right eye, with $+2.75 \mathrm{D}$ cyl., axis $45^{\circ}$, $6 / 24 \mathrm{ptly}$, and in the left eye, with $+2 \cdot 75 \mathrm{D}$ cyl., axis $120^{\circ}, 6 / 24$.

Case 16, male, born $24.7 .48,8$ weeks premature, birth weight $2 \frac{1}{2} \mathrm{lb}$., in oxygen tent 3 weeks. Father has nystagmus but neither parent myopic.

Both eyes showed a rapid lateral nystagmus.

Right eye about $10^{\circ}$ convergent, media clear apart from a few very fine vitreous opacities; disc pale, vessels rather narrow, macula slate-grey and slightly elevated. Visual acuity, with $-4 \mathrm{D}$ sph., $-0 \cdot 75 \mathrm{D}$ cyl., axis $15^{\circ}, 3 / 60$.

Left eye presented the same appearance as the right. Visual acuity, with $-0.75 \mathrm{D}$ sph., $-0.75 \mathrm{D}$ cyl., axis $180^{\circ}, 3 / 60$ :

The nystagmus in this child was much faster and more rhythmical than in the other cases in this series, and was probably hereditary in nature (see above). The appearance of the maculae corresponded to that of the other cases of retrolental fibroplasia.

(B) Cases in which the possibility of retinopathy of prematurity was considered after examination. The ocular findings are given first, and the birth history subsequently, to emphasize this fact.

Case 17, male, born 25.5.50, was referred as a case of "congenital myopia". Neither parent myopic. There was a moderate amount of general retardation.

Both eyes showed a fine rotatory nystagmus; subjective refraction was impossible but visual acuity was estimated at $6 / 36$.

Right eye, anterior chamber normal, no synechiae. Iris blue. The lens was clear, whilst the vitreous showed a fine strand of opacity and numerous fine dust-like opacities. A large crescent surrounded the right disc, the retinal vessels appeared normal, but the macula showed fine stippling. Towards the periphery of the fundus were coarser patches of pigmentation of the pepperand-salt type. Retinoscopy showed a high degree of myopia. Refraction -15 D sph., -2 D cyl., axis $90^{\circ}$.

Left eye convergent and small and the ocular tension raised. Cornea clear, anterior chamber shallow, and iris greyish. The pupil did not react to light. The lens was clear. Fine dust-like opacities were present in the vitreous, together with a localized retrolental membrane in the lower temporal quadrant from 3 to 6 o'clock, appearing as a triangular fold stretching up to the disc. 
The latter was grey in colour and showed distortion of the vessels. Where the retinal vessels were visible, they appeared tortuous. The periphery of the retina showed large patches of pigmentary disturbance, discrete, pale, rather refractile areas, with pigment tending to deposit at the margin. Refraction + 2 D sph.

This child was born at 28 weeks, weight $2 \mathrm{lb}$. $7 \frac{1}{2} \mathrm{oz}$., in oxygen tent 8 weeks.

Case 18, female, born 29.4.47, was referred as a case of myopia. Neither parent myopic; no family history of myopia. The child was frail and delicate and had had an operation for cleft palate.

Right eye, visual acuity, with $-7 \mathrm{D}$ sph., $-0.5 \mathrm{D}$ cyl., axis $90^{\circ}, 6 / 12$.

Left eye, visual acuity, with $-7 \mathrm{D}$ sph., $-0.5 \mathrm{D}$ cyl., axis $80^{\circ}, 6 / 12$.

Both eyes, media clear. Irides blue. The discs showed commencing crescent formation; the vessels were normal. The retina appeared greyish in patches, and at the periphery showed some fine stippling and some small patches of pigment. The fundus appearances in this case appeared to represent the most minimal stage of retinopathy of prematurity.

This child was one month premature, birth weight $3 \mathrm{lb} .12 \mathrm{oz}$., in oxygen tent one month.

Case 19, female, born 3.4.42, was one of triplets, of which two girls survived, and a boy died 8 hours after birth. The eye condition was originally diagnosed as myopia.

In 1949 the refraction in the right eye was $-4 \mathrm{D}$ sph., $-1 \mathrm{D}$ cyl., axis $180^{\circ}$; and in the left $-9 \mathrm{D}$ sph., $-1 \mathrm{D}$ cyl., axis $180^{\circ}$. Visual acuity $6 / 18$ in both eyes.

When examined in December, 1955 , visual acuity in the right eye was $6 / 18$, with $-7 \mathrm{D}$ sph., $-1 \mathrm{D}$ cyl., axis $180^{\circ}$, and in the left eye $6 / 18$, with $-13 \mathrm{D}$ sph., $-1 \mathrm{D}$ cyl., axis $180^{\circ}$. The anterior segments of both eyes were normal, and the media clear. The outline of the right disc was obscured by glial tissue, and at both discs the vessels were distorted. The maculae appeared granular, the periphery showed patchy pigmentation, and the fundi were lacking in pigment.

This child was 6 weeks premature, birth weight $2 \mathrm{lb} .10 \mathrm{oz}$., in oxygen tent for an uncertain period.

Case 20, triplet sister of Case 19, birth weight $2 \mathrm{lb} .12 \mathrm{oz}$., also in oxygen tent for an uncertain period.

In 1950 the refraction in the right eye was $-10 \mathrm{D}$ sph., $-1.5 \mathrm{D}$ cyl., axis $170^{\circ}$; and in the left $-12 \mathrm{D}$ sph., $-2 \mathrm{D}$ cyl., axis $120^{\circ}$.

In December 1955 : visual acuity in the right eye, with $-11 \mathrm{D}$ sph., 6/18 (6/12 ptly); in the left eye, with -13 D sph., $6 / 18$.

Both eyes anterior segments normal, fine vitreous opacities. There were crescents at both discs, with some tortuosity of the vessels at the nerve head. Both maculae appeared spongy and granular and the foveae appeared ill-developed, while at the periphery the retina showed fine granular pigmentation.

Cases 19 and 20 had been examined on several occasions before it became apparent that some of these findings corresponded to those seen in retrolental fibroplasia. There was no myopia in either parent, but inquiry revealed the significant factors in their early history. Both twins had blue eyes.

Case 21, male, born 2.1.47, was ascertained as suffering from 'high myopia'. No family history of myopia.

Right eye showed a convergent squint and was rather smaller than the left. Visual acuity counting fingers at 6 inches, no retinoscopy was possible, but examination of the fundus showed fine vitreous opacities. The outline of the disc was blurred, probably partly because of the opacities in the media, the vessels were attenuated, and there were patches of choroidoretinal pigmentary disturbance, larger than the optic disc.

Left eye showed some fine nystagmoid movements. Visual acuity, with $-10 \mathrm{D}$ sph., $-1.5 \mathrm{D}$ cyl., axis $30^{\circ}, 6 / 18$. Stringy opacities were present in the vitreous, and the vessels at the disc were distorted. The retina showed an ill-defined, elevated grey patch in the periphery of the temporal quadrant, at 3 o'clock.

This child was 8 weeks premature, birth weight $4 \frac{1}{2} \mathrm{lb}$., in oxygen tent 8 weeks. 
Case 22, female, born 3.8.51. Parents not short-sighted.

Both eyes showed a high degree of myopia.

In July, 1954, the refractions were: right eye $-9 \mathrm{D}$ sph., $-0.5 \mathrm{D}$ cyl., axis $180^{\circ}$; left eye $-5 \mathrm{D} \mathrm{sph} .,-4.5 \mathrm{D}$ cyl., axis $180^{\circ}$.

In February, 1955 , the myopia had increased to : right eye $-10 \mathrm{D}$ sph., $-0.5 \mathrm{D}$ cyl., axis $180^{\circ}$; left eye $-6.5 \mathrm{D}$ sph., $-2.5 \mathrm{D}$ cyl., axis $170^{\circ}$.

Subjective estimation of the visual acuity was not possible. Irides blue. The media were clear, the discs appeared large and slightly pale. Both maculae appeared granular but marked depigmentation of the retinae was evident.

This child was born at 28 weeks, birth weight $2 \mathrm{lb}$. $15 \mathrm{oz}$., in oxygen tent 4 weeks. Case 23, female, born 4.6.48, was thin, rather restless and excitable, but of average intelligence.

Right eye was highly myopic, visual acuity with $-9 \mathrm{D}$ sph., $-2 \mathrm{D}$ cyl., axis $55^{\circ}, 6 / 36$. Anterior segment normal, and lens clear. Iris brown. The retina showed some thinning and some fine vitreous opacities were present.

Left eye convergent, smaller than the other, with no fixation; it was doubtful if there was perception of light in that eye. On examination, the anterior segment was normal, the lens clear. The fundi showed scattered areas of pigmentary disturbance including a large patch the size of the disc at the posterior pole. A localized detachment of the retina was present in the lower and outer quadrant, with a fold of retina stretching up towards the disc.

This child was 8 weeks premature, birth weight $2 \mathrm{lb}$. $6 \mathrm{oz}$., in oxygen tent for an unknown period.

Case 24, female, born 5.2.46, was rather small and undersized for her age. Neither parent myopic.

Right eye, visual acuity, with $-5 \mathrm{D}$ sph., $-1 \mathrm{D}$ cyl., axis $15^{\circ}, 6 / 12$. Anterior segment normal, lens clear. Iris brown. The vitreous was clear, and the disc normal in appearance. Some pigmentation was present at the right macula and fine pigmentation was present at the periphery.

Left eye, small and convergent, lens clear, but a dense retrolental membrane was present. No perception of light.

This child was born at 26 weeks, birth weight $2 \mathrm{lb} .4 \mathrm{oz}$., in oxygen tent 8 weeks.

Case 25, female, born 22.10.47, was admitted to a school for the partially sighted as a case of myopia. In the course of routine examination, it became apparent that her eyes showed similar clinical features to the cases previously examined.

Both eyes. Irides blue.

Right eye externally normal, ocular movements full; the eye deviated upwards under cover. The vitreous showed fine opacities. The disc appeared large and slightly pale, as is encountered in myopia; the vessels were kinked at the disc before spreading out into the retina, where they showed some tortuosity at the periphery. Fine pigmentary stippling was present at the macula, which appeared rather more spongy and vascular than normal. A patch of retinal atrophy about the size of the disc was present in the periphery at 9 o'clock, and the fundus was lacking in pigment. Visual acuity, with $-10 \mathrm{D}$ sph., 6/12.

Left eye externally normal but fixation poor. Numerous opacities in the anterior vitreous partly obscured fundus details. The disc was paler than that of the other eye, and the lower margin was sharply demarcated with a deep colobomatous appearance; the fundus showed a general lack of pigment, and several large patches of choroidoretinal atrophy. Visual acuity, with $-8 \mathrm{D}$. sph., $-3 \mathrm{D}$ cyl., axis $150^{\circ}, 3 / 60$.

This child was 10 weeks premature, birth weight $2 \frac{1}{2} \mathrm{lb}$., in oxygen tent 9 weeks.

Case 26, male, born 16.2.51, was brought by his mother on account of a squint in his right eye, which had been present from birth. Neither parent myopic.

Both eyes. Irides blue.

Right eye showed a marked convergent squint, with some weakness of the right superior rectus, and over-action of the right inferior oblique. The vision was difficult to assess, but in the right eye it was obviously extremely poor, fixation being lost. Ophthalmoscopic examination showed opacities in the vitreous and a localized detachment of the retina in the upper nasal quadrant. Refraction emmetropic. 
Left eye relatively normal but showed some lack of pigment and thinning. Refraction $-3.5 \mathrm{D}$ myopic.

This child was born at 6 months, birth weight $2 \mathrm{lb} .11 \mathrm{oz}$, in oxygen tent for 3 months.

Case 27, female, born 1.11.49, was examined at a school for the partially sighted at the age of 6 years. No family history of defective vision.

Both eyes showed nystagmus and eccentric fixation, and the left eye showed a slight convergence. The media were clear. Both optic nerve heads were distorted and the retinae were depigmented and thin. Both maculae showed fine pigmentary stippling.

Right eye, visual acuity, with $-3.5 \mathrm{D}$ cyl., axis $180^{\circ}, 6 / 36$.

Left eye, visual acuity, with $-4 \mathrm{D}$ sph., $-3.5 \mathrm{D}$ cyl., axis $180^{\circ}, 6 / 36$.

This child was 10 weeks premature, birth weight $2 \mathrm{lb} .12 \mathrm{oz}$., in oxygen tent several weeks.

Case 28, male, born 16.11.46, was examined at a school for the partially sighted at age of 7 years. No family history of myopia.

Both eyes, anterior segments of globes appeared normal. Irides blue.

Right eye, media clear, disc distorted and one or two spots of pigmentation were evident at the periphery together with degenerative changes and patches of mottling. Visual acuity with $-16 \mathrm{D}$ sph., 6/12 (6/9 ptly).

Left eye showed a convergent squint of about $25^{\circ}$. The vitreous showed numerous opacities, and the disc was distorted. The retina showed marked thinning with fine pigment stippling at the macula. Visual acuity, with $-11 \mathrm{D}$ sph., $4 / 60$.

This child was born at 7 months, birth weight 3lb., but was not given oxygen therapy.

Case 29, male, born 20.5.48, was brought for general medical examination at the age of 7 as a case of spastic diplegia and was noted to have an eye defect. Neither parent myopic.

Both eyes showed nystagmus, and fixation in the right eye was poor. Irides blue.

Right eye, visual acuity perception of light only; a retrolental mass of fibrous tissue was seen in the lower temporal quadrant.

Left eye, visual acuity less than $6 / 60$ unaided, but $6 / 36$ with $-5.5 \mathrm{D}$ sph., $-1.5 \mathrm{D}$ cyl., axis $180^{\circ}$. The vitreous showed numerous opacities and the retina showed thinning.

A diagnosis of retrolental fibroplasia was made. This child, one of twins, was 8 weeks premature, birth weight $3 \mathrm{lb} .2 \mathrm{oz}$., in oxygen tent 1 week.

Case 30, female, born 17.3.48, in the U.S.A., was brought for examination to determine her educational needs at the age of 7 years. The mother gave a history that an eye defect was noticed at the age of 8 months, when the eyes were noticed to be crossing. At the age of 2, the left eye was given atropine occlusion, in an endeavour to improve the acuity in the right eye, and spectacles were worn between the ages of 2 and 4 . In February, 1953, the child was noticed to be feeling for objects and an ophthalmologist diagnosed a detached retina in the left eye. The mother stated that four operations (two scleral resections and two diathermies) had been performed without success. Mother myopic, and stated that the maternal grandmother and two aunts were also myopic.

Right eye visual acuity $2 / 60$ and N.24 fixing eccentrically. Iris blue. Vitreous showed numerous. opacities, disc distorted in appearance, and vessels markedly tortuous. The retina was pale and thin and the periphery of the fundus showed patches of choroidoretinal atrophy. Refraction myopic; visual acuity, with $-4.5 \mathrm{D}$ sph., $-1.5 \mathrm{D}$ cyl., axis $105^{\circ}, 3 / 60$.

Left eye visual acuity perception of light only. The eye itself was microphthalmic and slightly congested. Iris grey. A secondary cataract had developed.

This child was 3 months premature, birth weight $2 \mathrm{lb}$.; in oxygen tent 3 months. The diagnosis was considered to be retrolental fibroplasia. 